\title{
BRICS Countries \\ And Their Strategic HRD Agenda In 2020
}

Nadir Ali Kolachi, Skyline University, UAE

Haider Ali Shah, University of Hertfordshire, UK

\begin{abstract}
This paper will discuss HRD's future in BRICS countries, focusing on an 11-point agenda specially designed for them. These nations are building a consortium to tackle HRD issues and enhance their quality of life by addressing issues such as health, safety, inadequate income, widespread hunger, gender inequality, environmental degradation, virulent diseases, and lack of technological expertise. They intend to promote BRICS and build global partnerships for longterm development and sustainability. This paper will also discuss BRICS' strategic HRD practices that are rapidly achieving their objectives. The BRICS have been investing in knowledge-based projects for many years as they believe that growth requires a knowledge economy. This paper will focus on the BRICS' nurturing of intellectual capital and evaluates the trend in BRICS' HRD practices as they follow their knowledge-based 11-point agenda.
\end{abstract}

Keywords: Strategic HRD; BRICS; Eleven-point (11-point) Agenda

\section{INTRODUCTION}

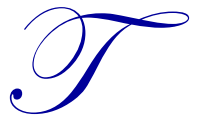

he BRICS nations comprise a consortium of five rapidly growing economies - Brazil, Russia, India, China, and South Africa. The acronym "BRIC," coined by Goldman in 2001, later became "BRICS" when South Africa joined in 2010. They are not only becoming the hub of natural resources, hydrocarbon reserves, production, consumption, technology, and forward-looking opportunities, but they are equally significant builders of human capital based on best HRD strategies. As of 2012, the five BRICS countries represent almost 3 billion people, with a combined nominal GDP of US\$13.7 trillion and an estimated US\$4 trillion in combined foreign reserves. Their cultures vary, but they have achieved success in many common areas. The focuses of their HRD practices are very similar - they have initiated various cooperative programs to balance HRD domains among them. The world's leading corporations have always focused on their organizational objectives in order to achieve them through the best possible means. To understand their organizational objectives, they need to understand the management objectives for which they invest in IC (intellectual capital) and FC (financial capital). To this end, corporate leaders seek the tools that will allow them to survive in our fast-paced, rapidly evolving, technological era. A small company of 500 people and a large corporation of 500,000 people both need to draw from an intellectual pool that will entice financial capital into their company. One of the biggest tools for achieving this is HRD which opens avenues and allows companies to make effective use of human resources in many ways, especially through organizational development, organizational change, career management, and training. Training is seen as the strategic HRD tool that builds human capital and enhances the capability of a workforce.

The BRICS countries have adopted this strategic approach in order to survive and succeed. This paper will report on the BRICS' micro- and macro-level plans for implementing their HRD strategies, the most common of which are communication, accountability and ownership, cost reduction, intrapreneurship, culture building, system training, learning, technology layers utilization, and equipping the workforce with workflow automation facilities.

This paper will discuss these strategies through a comparative focus on the 11-point agenda. 


\section{Eleven-point Agenda for BRICS' Strategic HRD}

1. HRD and BRICS' Internal Coordination

2. HRD and BRICS' International Coordination

3. HRD Learning (Education, Training, and Research)

4. HRD Competencies (Expertise, Exposure, and Efforts)

5. HRD Laws (Regulations, Security, and Health and Safety)

6. HRD and Youth Contribution to Technology Development

7. HRD and Roles (Government, Media, and Individual)

8. HRD Styles (Entertainment, Cultures, and Management Styles)

9. HRD in Small Businesses, Top Organizations, and Giants

10. HRD and Its Strategic Approach to Intellectual Capital Development

11. HRD and Challenges (CSR, Quality Management, and Implementations)

These agenda points will be analyzed through an appropriate case-based approach.

\section{LITERATURE REVIEW}

This paper evaluates the importance of the eleven-point agenda, the achievement of which will lead BRICS to become global economic leaders. The World Development Report has asserted that knowledge, not capital, will be the key to sustained economic growth and improved human welfare (World Development Report, 1998 and 1999). The BRICS nations are investing heavily in building their human capital, a recently adopted focus. This paper will discuss the strategic HRD aspect of the BRICS' initiatives, an approach similar to that followed by developed nations as they created their huge platform for the world's best education and technical training, which helped them launch many small companies and become world leaders. This model is being adopted and implemented by the world's leading emerging markets, and especially by the BRICS countries, which have attracted global attention to their talent, education, technical knowledge, people management, and large investment in intellectual capital.

The BRICS countries are achieving the above agenda points through one key strategy: real-time HRD practices, especially training, OD, and career management. These practices help build intellectual capital and spur a continuous development that produces talent. This speech is about how BRICS are managing, achieving, and maintaining their strategic HRD goals. Brazil is focusing on its own style; Russia has learned and adopted many new practices; India is changing the world's perception of it through development; China has become self-reliant, and South Africa continues to progress despite its problems. China and India are both on the verge of large development projects. These countries' successes are entirely due to their investments in HRD projects. This success is not limited to America, the UK, or the BRICS; any nation can be successful through intellectual development investments, via strategic HRD initiatives. Chinese and Indian infrastructure and African financing are at par with investments from traditional donors (The Infrastructure Consortium for Africa, 2008). Moreover, investments have shifted to agricultural development, debt relief, and the expansion of preferential access (FOCAC, 2009; Forrester et al., 2009). Developed nations have built their HRD by giving an equal chance to everyone to a degree not often seen in developing nations. The basic HRD approach is to build talent and then create an opportunity; developing nations need to allow everyone a chance and thereby identify talent, and the BRICS countries have taken effective initiatives to this end. Some have opportunities but no talent; some have talent but no opportunities. The BRICS countries have decided to use their advantages. They must meet this challenge to developing and emerging markets; the BRICS countries are approaching their targets.

In addition to their HRD focus, the BRICS countries are growing their GDP through competition within the BRICS group. The BRICS' GDP levels have been considered good, but projections vary. India's 2045-50 growth has been projected at $4.9 \%$, Brazil's at $3.4 \%$, and China's (with a forecasted population decline) at $2.8 \%$ (Gold Sachs, Global Economic Paper No. 134: How solid are the BRICS?). China's projections are positive. The Financial Times reports that China is moving successfully up-market (Financial Times, July 5, 2006). All processes and systems require HR and Personnel Management. Many trends emerge and vanish, but HR needs to keep evolving through increased demand. Moreover, HRD is a pre-requisite for the proper identification and organization 
of corporate functions in our fast-paced and ever-changing technology-driven economy. Companies and nations that wish to be leaders must understand the changing global trends through the support of HRD practices. Defining everything with reference to HRD will guarantee success.

Top management philosophers examine the available opportunities and determine how people, companies, and countries can best succeed. To do this, they assemble the resources offered via HRD techniques and strive toward their goals. This happened at GE where Jack Welch unleashed the workers' energies and achieved wonders. It happened in Vietnam whose people have attracted global support and investment. It happened in the European Union which surprised the world with its freedom and coordination. It happened through Mian Mansha who created an effective banking sector in Pakistan. It happened through Mohammad Younus who made Bangladesh very successful through micro-financing. It happened in the Emirates and at Microsoft and Airtel. It happened through N. Murti who started a company with just a few rupees and now has millions in turnover. This is happening among the BRICS at an even faster pace, which quickens every day. This is how Brazil became the South American leader, Russia a global power, and China a survivor in difficult times. Incredibly, India has become globally significant many Indians do not have a roof to sleep under, yet Indian intellectuals can be found throughout the world's universities and Indian products can be found in European stores. South Africa has become a global favorite. The world was long unipolar, with the USA the sole superpower. The world became bipolar when Russia attained superpower status. Today, the world is multipolar, with many powerful nations working on their HRD techniques. Education and HR are the main pillars of this multipolar reality. In fact, "BRICS" could stand as an acronym for "multipolar" since the group decided to leave the dollar as the Chinese and Koreans had done a few years before. Power is being shared among small regions and groups like SAARC, ASEAN, MERCOSURE, SAFTA, the EU, and the BRICS who all seek to coordinate and help each other by sharing their advantages.

\section{BRICS' STRATEGIC HRD PRACTICES (ANALYSIS)} strategies:

The following three HRD practices are very common among BRICS countries' global competition

- $\quad$ Organizational Development (Brazil, Russia, China) - These three countries are proactive. They use models and systems to change their processes according to their cultures, resources, and leadership.

- Career Management (Brazil, Russia, India, China, and South Africa) - This is followed by all BRICS countries.

- $\quad$ Training and Development (India and South Africa) - India and South Africa are very flexible in adapting to different cultures. Their post-colonial backgrounds help them communicate with developed countries, especially the USA and the UK, from whom they have borrowed many HRD practices and training techniques in high demand in the middle hierarchy of the top MNCs. Indians and South Africans adjust to MNCs easily due to their strong communication and English skills.

\subsection{Brazil}

Brazil enjoys good standing in South America. Its internal coordination with BRICS is very positive as it seeks to attract Chinese investment, Indian labor, Russian learning models, and African sports. Brazil also enjoys good relationships with the USA and MERCOSURE countries. Brazilian training is rigorous, especially that on behalf of modernization. Brazilians are very independent and value US education. They are working hard toward HR development; with little prior HR experience and a long dependence on US models, they have initiated several attractive nation-building projects. The partnership between UNESCO and the Brazilian government in the national policy on youth is helping build youth capability and represents an investment in the future. Technology use is very common in Brazil. They depend on an array of laws that help the Brazilian community, such as non-competitive laws that protect Brazilian jobs and SMEs. Brazil has become a good ergonomics practitioner and all companies operating there must obtain an ergonomics certificate. Brazilian culture is very independent, friendly, open, and easily accommodates many cultures. Brazil's top-down communication sometimes involves too much discussion and debate. The key concept in their culture is relationship. Brazilians are building their HRD through open access, interaction, and flexible hours. They usually enjoy lunch breaks, remain together for awhile, and then scatter toward their offices. They have a built-in strategic approach that they are implementing while taking full advantage of 
BRICS companies, especially Indian and Chinese ones. To assure an accurate HRD development, they use the MCOD (Multicultural Organizational Development Models) approach which helps them work with a variety of nationalities. They also depend on the US, France, Spain, and Portugal. Training and development is one area in which they are working hard to keep pace with other BRICS coordinators. They are also working on quality management which is a relatively new concept to them. They have started to focus on specific HRD initiatives in coordination with the government.

\subsection{Russia}

The Russians are working at a much higher HR level. Their HRD has been weak, but their personnel administration has been relatively strong. Russia's HR development began when twenty Moscow firms offered training in HRD-related strategies and management models. Western programs were not easily accepted by the Russians, who took a long time to comprehend the importance of pre-training attitudes. Knowledge-based training was provided in Russian, which helped them understand the issues facing their culture and launched the process in the right direction. Russians are now sent to America's top MNCs to see, adapt, watch videos, and perform other ghost marketing activities to improve their skills. Peter the Great transformed his backward nation into one of the most powerful in the world. Through his vision, he instilled the importance of developing his people for the sake of "Mother Russia". He made his people very ambitious. The Russians enhanced their HRD initiatives on an international scale and decided to implement them on a massive national scale. While aiming to acquire the best machines and weapons, HRD was not their focus. Now it is; they want to achieve the best and have started achieving it. The day is not far off when they will dominate the planet. Today's Russia is technologically, economically, and globally integrated. Russian leaders are driving their people to build their HR skills. They have evaluated the best training trends, best educational activities, and best artilleries, and have covered most development domains in the process of revealing to the world the effectiveness of their HRD activities. Today's Russian competency is very high in many areas, especially in invention, design, and manufacturing. They have everything that their natural resources can produce. The Russian government has been very active in building a culture adaptable to BRICS activities. The government has evaluated what is required and has provided education and HRD with large investments that foster intellectual capital development. Russian managers and leaders are striving to make their companies number one and are restructuring and investing in HRD on larger scales. Russians are pursuing every possible solution and are borrowing HR innovations from foreign experts as they are facing time limitations.

\subsection{India}

India is probably the top HRD builder among the BRICS countries. It has a considerable advantage of being an English-speaking nation and having the best education. Since its independence, and particularly during the 1950 s and '60s, India sent students to Harvard, Stanford, Oxford, and other top universities. After their studies, they returned and built IT companies and other flourishing businesses. Through this process, they learned the best training methods and management techniques. All the top universities now offer summer courses in India. This has led to Indians acquiring positions in the middle hierarchies of all top MNCs. India suffers from political problems, but these have not hindered its exponential growth. India's internal coordination with the BRICS is very healthy and has attracted Brazilian investment and Chinese expertise. India is good friends with the USA and the UK and has received much exposure in the foremost developed countries. India possesses both competency and competiveness, which are attracting world attention. Youth is one of a nation's greatest resources. In few Asian countries, $60 \%$ of the population is under 25 years old (in Pakistan, Bangladesh, and India). India's youth is more dynamic. You can find Indian youth and senior personnel in every part of the world where they have proven to be innovative and intelligent. The Indian government's media image is somewhat unfavorable, but the nation's educated people are branding India globally. While HRD is not the only development vehicle, India is working on it to equip Indians with skills in various fields. India is building higher education models while fostering research, engineering, and IT excellence. India's Bollywood and IPL sports are growing daily. One Indian initiative was to ask MNCs to work on a single project, solve the problem in question, and have all MNCs adapt accordingly. Today, MNCs' work is effectively organized with some working on health, some on education, and some on sports, among many other domains. India focuses on corporate accountability rather than on mere corporate social responsibility. 


\subsection{China}

China maintains an effective internal coordination with other BRICS. China is learning very quickly and is adopting what is good in the HRD models, and their education has greatly improved over the years. China is selfsufficient, with highly skilled engineers and policymakers, and they are needed by many countries. Chinese culture is very different from that of many other countries and their education is based on Confucianism. The Chinese use HRD in many different ways; for example, they follow guanxi, the concept that personal connections are important for business dealings. They also support their own companies through zhongjian ren. Most important of all is social status (shehui dengji). They freely offer respect and expect the same from other people. Chinese laws are favorable to most Chinese companies. Their culture is based on morality and pictography, and they are quick learners. Like India, China has sent people to developed nations to learn IT and business techniques and then return to develop huge HRD domains. They have experiences of many countries and are familiar with all the significant models, not just American and British ones. A decade ago, their only expertise was technical, but they have now mastered all domains. They have innovated new training models and HRD perspectives.

\subsection{South Africa}

South Africa is the world's biggest emerging market, with many resources and initiatives through which they are fostering a competitive youth. Its internal coordination is good, but kudos go to China who invited them into BRICS in 2010. South Africa, which receives international aid, gained much by hosting World Cup soccer. South African education is high quality, but its human quality-of-life index was low as of 2011. South Africa's HRD initiatives have occurred through technical developments. They have innovated in business and the IT sector. The government is supportive but needs to become as supportive as the Russian government. South Africa is learning from Russia and India.

\section{COMPARATIVE MATRIX OF BRICS HRD INITIATIVES}

Table 1 is a comparative matrix that was developed on the basis of primary sources and discussions among BRICS authorities, including the authors, who have experience of and interest in BRICS HRD initiatives. The matrix was developed to guide readers through the BRICS 2020 plan to achieve high HRD in 2020 and foster an interest in BRICS countries and their initiatives. The data are not fixed but represent plans. This is a policy paper based on a case which is most suitable for the study in question. The scaling criteria run from 1 to 3 , where 1 means "improving," 2 means "good," and 3 means "has achieved the target." A total of 33 means "excellent", 22 means "good", and under 22 means "improving". This scaling is not an acute research instrument (which is not required in a study such as this) but is based on a practical trend analysis of the countries' development. This will allow policymakers, international businesses, managements, and international students to understand the potential of BRICS countries. The matrix evaluates the 11-point agenda for the HRD initiatives of the BRICS countries.

Table 1: Comparative Matrix of BRICS HRD Initiatives

\begin{tabular}{|l|c|c|c|c|c|}
\hline & & & & \\
\hline
\end{tabular}

2013 The Clute Institute http://www.cluteinstitute.com/ 


\begin{tabular}{|c|c|c|c|c|c|}
\hline Individual) & & & & & \\
\hline $\begin{array}{l}\text { HRD Styles (Entertainment, Cultures, } \\
\text { \& Management Styles) }\end{array}$ & 2 & 2 & 3 & 3 & 2 \\
\hline $\begin{array}{l}\text { HRD in Small Businesses, Top } \\
\text { Organizations, \& Giants }\end{array}$ & 2 & 2 & 2 & 2 & 2 \\
\hline $\begin{array}{l}\text { HRD \& its Strategic Approach in } \\
\text { Intellectual Capital Development }\end{array}$ & 2 & 3 & 3 & 3 & 2 \\
\hline $\begin{array}{l}\text { HRD and Challenges (CSR, Quality } \\
\text { Management, and Implementations) }\end{array}$ & 2 & 2 & 2 & 2 & 2 \\
\hline Total & 23 & 27 & 27 & 29 & 23 \\
\hline
\end{tabular}

According to the above analysis, all BRICS are doing better and some are very competitive. The BRICS' internal and external coordination is effective - they are helping each other. They are coordinating their absolute advantages and they are exchanging these advantages among each other while helping the BRICS become stronger.

\subsection{BRICS and HRD Challenges}

4.1.1 Technological (infrastructure, application)

4.1.2 Cultural (rules, norms, behavior, climate. and feelings)

4.1.3 Ethical (social responsibility, accountability, government role)

4.1.4 Legal (law and order)

4.1.5 Educational (learning and HRD)

4.1.6 Psychological (empowerment, professional dealing)

4.1.7 Organizational (government, cooperation, small business growth, capabilities, and outsourcing)

The BRICS nations are using large-scale HRD and are coordinating with one another to cope with the above challenges. China and India have recently stepped up to handle these challenges, not only in their own countries but throughout the entire BRICS family.

\section{RESEARCH METHODOLOGY}

This research is based on a case study that draws on the practical viewpoints of experts involved in BRICS development. Most of the data are primary, but a few Internet references were consulted. We selected the five BRICS countries in order to understand their development in HRD domains. We consulted a literature survey and interviewed policymakers to understand HRD plans and usage in BRICS countries. The interviews were unstructured based on the policymakers' availability. A comparative matrix was developed to help readers understand the trend in BRICS countries using the authors' research on the 11-point agenda. The main research objective was to identify the BRICS' strategic HRD agenda for 2020. To this end, a case-based research approach was adopted and general scaling criteria (described above) were designed to evaluate the eleven agenda points among BRICS countries. The scaling criteria spanned from 1 to 3, with 1 meaning "improving", 2 "good", and 3 "has achieved the target". A total of 33 means "excellent", 22 means "good", and under 22 means "improving". This scaling is not an acute research instrument (which is not required in a study such as this) but is based on a practical trend analysis of the countries' development. This will allow policymakers, international businesses, managements, and international students to understand the potential of BRICS countries. The matrix evaluates the 11-point agenda for the HRD initiatives of the BRICS countries. The data for this research analysis were acquired through the proposed scaling mentioned above. The agenda items were put into the scaling, which evaluated the standing of each BRICS country. The criteria for the scaling points were based on the literature survey, trend analysis, BRICS reports, BRICS meetings, and the authors' knowledge. The analysis shows that China is leading in strategic initiatives, while India and Russia are the leading BRICS regions overall. Furthermore, Brazil and South Africa are following the pace set by China and Russia. The comparative matrix in the analysis shows that BRICS' important 2020 agenda item is a move toward HRD initiatives. 


\section{CONCLUSION}

This paper concludes that BRICS are smartly following a cooperative agenda. The entry of every country to BRICS is an effort to acquire benefits from the other members. This analysis shows that everyone wants investment from China. India wants investment from Russia and Brazil. Brazil wants investment from Russia, and Russia wants many things from everyone else. BRICS countries are focused on resources and resourcefulness. Many emerging markets have resources that they cannot exploit. Resourcefulness - the ability to utilize resources - is something the BRICS nations have displayed more than other emerging markets, like Indonesia, Malaysia, Iran, the Philippines, and Pakistan. The BRICS nations are able to manage whatever problems they may encounter. Democracy in India, autocracy in China, centralization in Brazil and Russia, and decentralization in South Africa are all moving in the right direction while implementing the best HRD practices. The developing nations still unable to compete are those less willing to adopt HRD techniques. Whether it is the USA, the UK, France, Germany, or any other successful country, they are successful only insofar as they follow the right HRD practices. BRICS are nearly HRD BRICS, and others may join. This research concludes that BRICS competency levels have been enhanced through BRICS coordination. The BRICS bank initiative is on the agenda and may be implemented soon. The BRICS' strategic HRD is the main concern. This research has found that all BRICS countries need eleven agenda points in 2020 but that none of the BRICS countries fully possesses those agenda points. India and China have certain technological advantages, while South Africa, Russia, and Brazil have many resources. The research also indicates that India and China are ready to manage their resources and learn from Russia and Brazil. The utilization of the eleven agenda points by the next eleven countries will be the object of future research.

\section{AUTHOR INFORMATION}

Dr. Nadir Ali Kolachi is an Associate Professor at Skyline University, University City of Sharjah, UAE. He has more than fifteen years of training, teaching, consultancy and research experience at National \& International levels. Dr. Kolachi has earned an MBA, MS and PhD in Management. He has delivered many Keynote Speeches \& Research presentations on Management, HR, HRD, Change Management, OD, Management Education, Public Administration, Corporate Leadership and Organizational Communication in USA, UK, Poland, Italy, Portugal, Pakistan, India and UAE. He is a Certified Corporate trainer of GAMMP International (Global Association of Management \& Marketing Professionals). E-mail: nadir.kolachi@gmail.com (Corresponding author)

Dr. Haider Shah is an Associate Professor at Business School, University of Hertfordshire, UK and has been in the teaching profession for many years. He teaches public policy at the Business School, University of Hertfordshire, UK. Dr. Shah is a regular writer in the Daily Times, a renowned newspaper in Pakistan, and has published many research papers and delivered various guest lectures in the UK. His areas of research and teaching are Public Administration, HR and Public Policy.

\section{REFERENCES}

1. Financial Times (2006), China is moving successfully up market (Financial Times, July 5, 2006)

2. FOCAC, 2009, Forrester et al. 2009, More than ever, there has been a shift towards supporting investment in agricultural development, debt relief, and the expansion of preferential access.

3. Gold Sachs (2005), Global Economic paper No. 134, How solid are the BRICS? (2005)

4. The Infrastructure Consortium for Africa (2008), Chinese \& Indian infrastructure, financing to Africa alone is now of a similar magnitude to that from traditional donors.

5. World Development Report $(1998,1999)$, Knowledge, not capital, would be the key to sustained economic growth and improvements in human well being (World Development Report, 1998, 1999). 


\section{$\underline{\text { NOTES }}$}

